\title{
Trajectories of relative weight and waist circumference among children with and without developmental coordination disorder
}

\author{
John Cairney PhD, John Hay PhD, Scott Veldhuizen MA, Cheryl Missiuna PhD OTReg(Ont), \\ Nadilein Mahlberg BA(Hons), Brent E. Faught PhD
}

Previously published at www.cmaj.ca

$\infty \infty$

See related commentary by Montgomery, page 1157

\section{ABSTRACT}

Background: Children with developmental coordination disorder have been found to be less likely to participate in physical activities and therefore may be at increased risk of overweight and obesity. We examined the longitudinal course of relative weight and waist circumference among school-aged children with and without possible developmental coordination disorder.

Methods: We received permission from 75 (83\%) of 92 schools in southwestern Ontario, Canada, to enrol children in the fourth grade (ages 9 and 10 at baseline). Informed consent from the parents of 2278 (95.8\%) of 2378 children in these schools was obtained at baseline. The main outcome measures were body mass index (BMI) and waist circumference. Children were followed up over two years, from the spring of 2005 to the spring of 2007.

Results: Over the course of the study, we identified 111 children (46 boys and 65 girls) who had possible developmental coordination disorder. These children had a higher mean BMI and waist circumference at baseline than did those without the disorder; these differences persisted or increased slightly over time. Children with possible developmental coordination disorder were also at persistently greater risk of overweight (odds ratio [OR] 3.44, 95\% confidence interval $[\mathrm{CI}] 2.34-5.07$ ) and obesity (OR 4.00, 95\% $\mathrm{Cl}$ 2.57-6.21) over the course of the study.

Interpretation: Our findings showed that children with possible developmental coordination disorder were at greater risk of overweight and obesity than children without the disorder. This risk did not diminish over the study period.

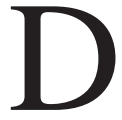
evelopmental coordination disorder is a neurodevelopmental condition that affects $5 \%-6 \%$ of school-aged children. ${ }^{\prime}$ Children with the disorder present with a range of coordination difficulties, including fine and gross motor problems, ${ }^{2}$ all of which interfere with normal daily activities, recreational activities and academic performance skills such as handwriting. ${ }^{3}$ Developmental coordination disorder is diagnosed when existing neurologic and physical problems are ruled out as the cause of motor coordi- nation difficulties and intellectual development has been taken into consideration (Box 1). ${ }^{1,4}$ The clinical implications of a diagnosis have been described previously.

Because children with developmental coordination disorder have been found to be less likely to participate in physical activities, ${ }^{6}$ it has been hypothesized that this condition may be a risk factor for obesity. ${ }^{7}$ Only a few studies have examined the association between motor coordination problems and overweight or obesity in children..$^{7-10}$ Moreover, the literature in this area is limited in two key respects. First, previous research has relied almost exclusively on body mass index (BMI) as the outcome measure..$^{8-10}$ Although important, BMI is not the only indicator of relative weight and has been shown to be weakly correlated with fat mass in young children. ${ }^{11,12}$ Waist circumference provides valid estimates of abdominal fat in pediatric populations $\mathrm{s}^{13}$ and appears to be a stronger predictor of cardiovascular risk among children. ${ }^{14,15}$ Second, previous research in this area has been limited to cross-sectional data, with two notable exceptions. ${ }^{8.9}$ However, results from these two prospective studies were mixed: one study showed a significant effect of motor coordination on weight, ${ }^{8}$ the other did not. ${ }^{9}$

Our objective was to document several measures of adiposity over time in children with and without developmental coordination disorder.

\section{Methods}

\section{Study population}

Ethics approval for the study design was obtained from the local district school board and Brock University. The study population comprised all children in the fourth grade (ages 9

From the Departments of Psychiatry and Behavioural Neuroscience (Cairney) and Family Medicine (Cairney), the School of Rehabilitation Science (Missiuna), and CanChild at the Centre for Childhood Disability Research (Cairney, Missiuna), McMaster University, Hamilton, Ont.; the Health Systems Research and Consulting Unit (Veldhuizen), Centre for Addiction and Mental Health, Toronto, Ont.; and the Department of Community Health Sciences (Hay, Veldhuizen, Mahlberg, Faught), Brock University, St. Catharines, Ont.

CMAJ 2010. DOI:10.1503/cmaj.091454 


\section{Box 1: Diagnostic criteria for developmental} coordination disorder

A. Performance in daily activities that require motor coordination is substantially below that expected given the person's chronological age and measured intelligence. This may be manifested by marked delays in achieving motor milestones (e.g., walking, crawling, sitting), dropping things, "clumsiness," poor performance in sports or poor handwriting.

B. The disturbance in criterion A significantly interferes with academic achievement or activities of daily living.

C. The disturbance is not due to a general medical condition (e.g., cerebral palsy, hemiplegia or muscular dystrophy) and does not meet criteria for a pervasive developmental disorder.

D. If mental retardation is present, the motor difficulties are in excess of those usually associated with it.

Reproduced with permission from the Diagnostic and Statistical Manual of Mental Disorders, Text Revision, Fourth Edition. ${ }^{4}$ Copyright $\odot 2000$ American Psychiatric Association.

and 10) in the 2004/05 school year in the public school system in the Niagara region of Ontario, Canada. We received permission from $75(83 \%)$ of 92 possible schools to enrol students. Informed consent from the parents of 2278 (95.8\%) of 2378 children at these schools was obtained at baseline. We established testing and training protocols, assembled a cadre of trained assistants, and completed pilot testing in the fall of 2004. Formal data collection began in the spring of 2005 (first wave). We followed the children through to the end of grade 6 , with reassessments done in the fall of 2005 (second wave), the spring and fall of 2006 (third and fourth waves) and the spring of 2007 (fifth wave). A total of 2083 children received motor testing; 103 were excluded from the multivariable models because of missing outcomes or other critical data, which left 1979 children in these analyses.

\section{Assessment of motor coordination}

Although repeated measures were taken for most assessments, motor coordination was assessed only once for each child. Developmental coordination disorder is a chronic condition that is present from birth, ${ }^{16,17}$ although it may not be detectable until early childhood. ${ }^{18,19}$ It generally does not improve with time..$^{20,21}$ Given this, and the expense of testing all children at the same point in the study, motor coordination was assessed across three different data-collection points. All 75 schools that agreed to participate were randomly divided into three groups. In the fall of 2005 , children in the first group of schools $(n=688)$ were screened for coordination difficulties; 36 were found to have possible developmental coordination disorder. In the spring of 2006, children in the second group ( $n=723$ ) were screened, and 39 children were found to have possible developmental coordination disorder. In the spring of 2007, children in the final group of 25 schools ( $n=672$ ) were tested, and 36 were identified as having possible developmental coordination disorder. To the best of our knowledge, none of the children had been evaluated for the disorder before the beginning of the study.

Reports detailing the results of the assessments of motor coordination and other measurements were sent to parents after each testing period. Parents of children who scored below the sixth percentile on the test of motor coordination received additional information on developmental coordination disorder, along with a letter explaining that children had not received a clinical assessment and that signs of poor motor coordination are common and not an indication of poor intellectual ability.

The data-collection procedures have been described in detail elsewhere. ${ }^{22}$ In brief, trained research assistants administered all assessments in the school gymnasium, where possible, and in other locations when necessary. A research coordinator and members of the core research team (J.C., J.H., B.F.) randomly observed testing to ensure data quality.

\section{Measurement of BMI and waist circumference}

Height and weight were measured using stabilometers (SECA, Hamburg, Germany) and precise electronic weight scales (Tanita, Tokyo, Japan). Waist circumference was measured midway between the lowest rib and the superior border of the iliac crest. ${ }^{23}$ Waist circumference was measured twice and the average of these measures recorded.

\section{Identification of developmental coordination disorder}

The Bruininks-Oseretsky test of Motor Proficiency (BOTMP) is one of the most commonly used standardized test in the identification of children with developmental coordination disorder. ${ }^{24}$ We evaluated motor coordination using the short form of this test (BOTMP-SF). The short form has been validated against the long form of the test, with correlations between 0.90 and 0.91 among children aged 8 to 14 years. ${ }^{25}$ The short-form BruininksOseretsky test was administered to the participating children in their school's gymnasium. Children who scored at or below the fifth percentile on the test (based on population-derived norms) were classified as having possible developmental coordination disorder. We described the disorder as "possible" because testing was administered on location by trained researchers, not as a diagnostic protocol administered by a physician. Moreover, our method did not include all of the four diagnostic criteria (Box 1). ${ }^{4}$ In this study, the short form of the Bruininks-Oseretsky test of Motor Proficiency was used to measure only criterion A; all participants who had known intellectual or learning disabilities or physical health problems (criteria C and D) were excluded. Of the 2083 children who received motor testing, 32 were removed for the analysis for these reasons. Criterion B was not measured.

A reassessment of a random sample of 24 children by a pediatric occupational therapist supported the validity of the testing approach. ${ }^{22}$ About two years after their original assessment, 77 children drawn from a randomly selected subset of schools were retested with the short form of the BruininksOseretsky test of Motor Proficiency by different examiners who were blind to the original results; the correlation between the two sets of scores was $0.70(p<0.001)$. We judged this to be acceptable, particularly because differences reflected any limitations of the instrument's test-retest and interrater reliability, as well as any changes in symptoms.

\section{Statistical analysis}

For BMI and waist circumference, we used mixed-effects modelling to estimate change within individuals over time, 
adjusting for correlation of measures within children (i.e., repeated-measures) and of children within schools. We included random intercepts at the school and student levels, as well as a random slope for time. Analysis of the data revealed possible seasonal effects, so we chose to use an unstructured covariance matrix. For both dependent measures, we fit models including time, possible developmental coordination disorder and sex, as well as all interactions among these measures. To model possible nonlinear patterns of change, we added a quadratic term for time.

We then used the age- and sex-specific cut-points derived by Cole and colleagues ${ }^{26}$ to create binary indicators of overweight and obesity and conducted a similar analysis to examine associations between possible developmental coordination disorder and these outcomes. Attempts to fit logistic three-level models resulted in problems achieving convergence with accurate fixed effects; however, school-level effects were shown to be modest and appeared to have little impact on estimates of fixed effects. We therefore modelled these outcomes using a generalized estimating equations approach, with repeated-measures, a logit link function and an unstructured covariance matrix. Because the effect of time appeared to be approximately linear for these outcomes, we omitted the quadratic term.

\section{Results}

Descriptive characteristics of the children at each wave of the study are provided in Table 1. At baseline, children with possible developmental coordination disorder had higher mean BMIs and waist circumferences than typically developing children. BMI differed by about $15 \%$, and waist circumference by about $12 \%$.

The results from the fixed-effects models for BMI and waist circumference are shown in Tables 2 and 3. In these models, we tested for a nonlinear effect of time and for interactions between time, sex and status of possible developmental coordination disorder. For BMI, we found significant interactions between time and sex and between time and possible developmental coordination disorder. For waist circumference, we found significant interactions between sex and possible developmental coordination disorder and between time and possible developmental coordination disorder; the

Table 1: Characteristics of children with and without possible developmental coordination disorder from enrolment in grade 4 (baseline) through grade $6^{*}$

\begin{tabular}{|c|c|c|c|c|c|c|}
\hline \multirow[b]{2}{*}{ Characteristic } & \multirow{2}{*}{\multicolumn{2}{|c|}{$\begin{array}{c}\text { Grade } 4 \\
\text { Wave } 1 \\
n=2278\end{array}$}} & \multicolumn{2}{|c|}{ Grade 5} & \multicolumn{2}{|c|}{ Grade 6} \\
\hline & & & $\begin{array}{l}\text { Wave } 2 \\
n=2227\end{array}$ & $\begin{array}{l}\text { Wave } 3 \\
n=2227\end{array}$ & $\begin{array}{l}\text { Wave } 4 \\
n=2086\end{array}$ & $\begin{array}{l}\text { Wave } 5 \\
n=2091\end{array}$ \\
\hline Age, yr, mean (SD) & & $9.9(0.5)$ & $10.4(0.5)$ & $10.9(0.4)$ & $11.3(0.4)$ & $11.9(0.4)$ \\
\hline \multicolumn{7}{|l|}{ Sex, \% (no.) } \\
\hline Male & 50.8 & $(1158 / 2278)$ & $50.9(1133 / 2227)$ & $50.9(1133 / 2227)$ & $50.5(1054 / 2086)$ & $50.6(1059 / 2091)$ \\
\hline Female & 49.2 & $(1120 / 2278)$ & $49.1(1094 / 2227)$ & $49.1(1094 / 2227)$ & $49.5(1032 / 2086)$ & $49.4(1032 / 2091)$ \\
\hline Possible DCD, \% (no.) & 5.3 & $(102 / 1942)$ & $5.2(103 / 1998)$ & $5.2(103 / 1998)$ & $5.2(101 / 1958)$ & $5.1 \quad(100 / 1960)$ \\
\hline \multicolumn{7}{|l|}{ BMI, mean (SD) } \\
\hline Possible DCD & & $21.2(5.1)$ & $22.0 \quad(5.1)$ & $22.4 \quad(5.7)$ & $22.8 \quad(5.5)$ & $23.4 \quad(5.5)$ \\
\hline No DCD & & $18.4(3.4)$ & 18.8 & 19.0 & $19.5(3.8)$ & 19.9 (3.9) \\
\hline All & & $18.6(3.5)$ & $19.0(3.8)$ & $19.3(3.9)$ & $19.7(4.0)$ & $20.1(4.0)$ \\
\hline \multicolumn{7}{|c|}{$\begin{array}{l}\text { Waist circumference, cm, } \\
\text { mean (SD) }\end{array}$} \\
\hline Possible DCD & & $72.3(13.6)$ & $75.9(13.5)$ & $78.2(13.7)$ & $80.0(14.5)$ & $81.7(14.7)$ \\
\hline No DCD & & $64.7 \quad(9.8)$ & $66.9(10.1)$ & $68.5(10.0)$ & $69.9(10.8)$ & $71.1(10.9)$ \\
\hline All & & $65.0(10.1)$ & $67.4(10.4)$ & $69.1(10.5)$ & $70.6(11.3)$ & $71.7(11.4)$ \\
\hline \multicolumn{7}{|l|}{ Overweight, \% (no.) } \\
\hline Possible DCD & 56.0 & $(56 / 100)$ & $(60 / 102)$ & $55.9 \quad(57 / 102)$ & $(58 / 99)$ & $(58 / 97)$ \\
\hline No DCD & 28.6 & $(520 / 1820)$ & $29.6(554 / 1871)$ & $27.6 \quad(512 / 1853)$ & $30.4 \quad(556 / 1828)$ & $30.5 \quad(552 / 1807)$ \\
\hline All & 30.1 & $(649 / 2155)$ & $31.2(658 / 2108)$ & $29.6 \quad(612 / 2070)$ & $32.1 \quad(655 / 2043)$ & $32.3(649 / 2007)$ \\
\hline \multicolumn{7}{|l|}{ Obesity, \% (no.) } \\
\hline Possible DCD & 29.0 & $(29 / 100)$ & $31.4 \quad(32 / 102)$ & $31.4 \quad(32 / 102)$ & $30.3(30 / 99)$ & $(32 / 97)$ \\
\hline No DCD & 8.7 & $(159 / 1820)$ & $9.9 \quad(185 / 1871)$ & $8.6 \quad(160 / 1853)$ & $9.2(169 / 1828)$ & $8.3 \quad(150 / 1807)$ \\
\hline All & 9.7 & $(210 / 2155)$ & $11.0 \quad(232 / 2108)$ & $10.0 \quad(207 / 2070)$ & $10.5(214 / 2043)$ & $9.8 \quad(196 / 2007)$ \\
\hline
\end{tabular}

Note: $\mathrm{BMI}=$ body mass index, $\mathrm{DCD}=$ developmental coordination disorder, $\mathrm{SD}=$ standard deviation.

*Wave 1 = fall 2004; wave 2 = fall 2005; wave 3 = spring 2006; wave 4 = fall 2006; wave 5 = spring 2007. The totals given with the column headings reflect the number of children in the study at each point; the denominators in the body of the table reflect the number of children for whom the relevant testing was completed. 
Table 2: Estimated change in body mass index over time in relation to time, sex and possible developmental coordination disorder in linear mixed-effects regression model

\begin{tabular}{lc}
\hline Variable & Estimated coefficient* $(95 \% \mathrm{Cl})$ \\
\hline Female sex & $0.01(-0.28$ to 0.3$)$ \\
\hline Age at baseline & $0.47(0.06$ to 0.87$)$ \\
Possible DCD & $3.28(2.29$ to 4.26$)$ \\
\hline Time, mo & $0.05(0.04$ to 0.06$)$ \\
\hline Time squared, mo & $2.9 \times 10^{-4}\left(1.4 \times 10^{-5}\right.$ to $\left.5.6 \times 10^{-4}\right)$ \\
\hline Possible DCD $\times$ time & $0.03(0.01$ to 0.04$)$ \\
Female sex $\times$ possible $D C D$ & $-1.25(-2.56$ to 0.06$)$ \\
\hline Female sex $\times$ time & $0.01(0.001$ to 0.01$)$ \\
\hline
\end{tabular}

Note: $\mathrm{Cl}=$ confidence interval, $\mathrm{DCD}=$ developmental coordination disorder *Coefficients represent the expected change in body mass index associated with an increase of 1 in the predictor variable.

interaction between sex and time was not significant. There was no evidence of a three-way interaction between these variables for either outcome $(p>0.10)$ so this term was not included in the final models.

The presence of significant, positive effects for the interaction between possible developmental coordination disorder status and time for both BMI and waist circumference indicated that differences in these outcome measures between groups over time was not static. In order to aid in the interpretation of this effect, we graphed the predicted values against time for both outcomes, assuming a baseline age of 10 years (Figures 1 and 2). We found that possible developmental coordination disorder was associated with more rapid increases in both BMI and waist circumference over the twoyear study period. The trajectories throughout this period were similar for both boys and girls, regardless of whether they had possible developmental coordination disorder.

The results of our analysis of the risk of overweight and

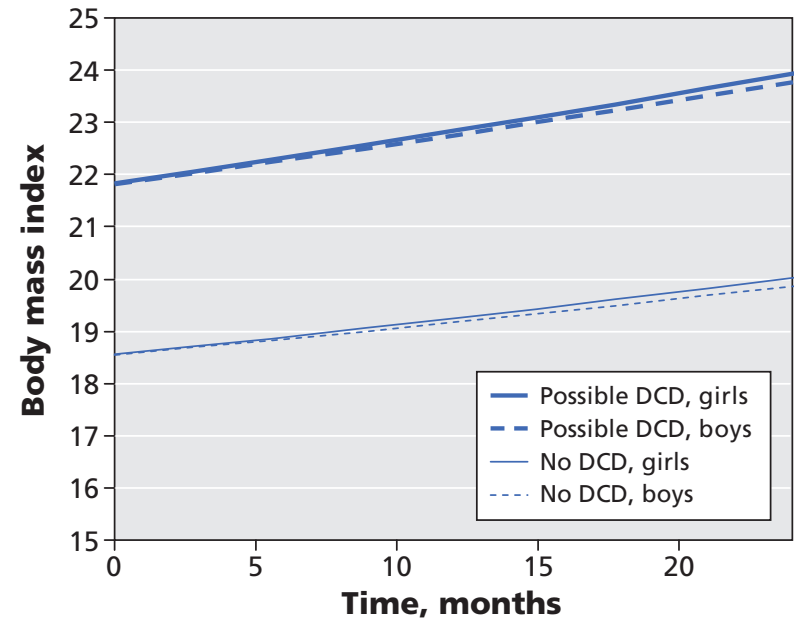

Figure 1: Predicted body mass index among children with and without possible developmental coordination disorder (DCD).
Table 3: Estimated change in waist circumference over time in relation to time, sex and possible developmental coordination disorder in linear mixed-effects regression model

\begin{tabular}{lr}
\hline Variable & Estimated coefficient* $(95 \% \mathrm{Cl})$ \\
\hline Female sex & $0.21(-0.6$ to 1.03$)$ \\
\hline Age at baseline & $10.73(0.59$ to 2.86$)$ \\
\hline Possible DCD & $9.53(6.77$ to 12.29$)$ \\
\hline Time, mo & $0.40(0.37$ to 0.43$)$ \\
\hline Time squared, mo & $-5.6 \times 10^{-3}\left(6.6 \times 10^{-3}\right.$ to $\left.4.6 \times 10^{-3}\right)$ \\
\hline Possible DCD $\times$ time & $0.10(0.05$ to 0.15$)$ \\
\hline Female sex $\times$ possible DCD & $-4.02(-7.68$ to -0.35$)$ \\
\hline Female sex $\times$ time & $0.01 \quad(0.01$ to 0.03$)$ \\
\hline
\end{tabular}

Note: $\mathrm{Cl}=$ confidence interval, $\mathrm{DCD}=$ developmental coordination disorder. * Coefficients represent the expected change in waist circumference associated with an increase of 1 in the predictor variable.

obesity associated with possible developmental coordination disorder are presented in Table 4. Because there are no consensus-based cut-points for waist circumference for either overweight or obesity, we limited this analysis to age-specific BMI cut-points derived from the work of Cole and coauthors. ${ }^{26}$ For overweight (Table 4), we found a significant main effect of possible developmental coordination disorder: children with possible developmental coordination disorder were more than three times as likely as those without the disorder to be overweight over the study period. We did not find a significant interaction between possible developmental coordination disorder and time, which suggests that the gap in overweight between children with and without possible developmental coordination disorder remained stable over time. We also found no effect of sex on the association between the disorder, time and overweight. Figure 3 is a plot of the predicted probability of overweight in both groups of children, derived using the equation from Table 4. Children with possible develop-

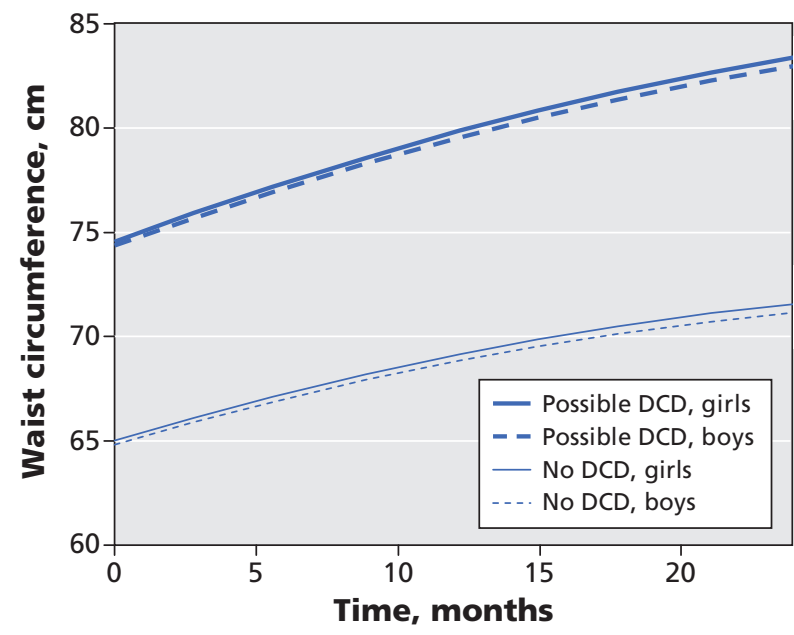

Figure 2: Predicted waist circumference among children with and without possible developmental coordination disorder (DCD). 
Table 4: Risk of overweight and obesity associated with possible developmental coordination disorder and sex

\begin{tabular}{lll}
\hline Variable & OR $(95 \% \mathrm{Cl})$ \\
\hline Overweight & 1.15 & $(0.95-1.39)$ \\
\hline Female sex & 1.00 & $(0.78-1.28)$ \\
\hline Age at baseline & 3.44 & $(2.34-5.07)$ \\
\hline Possible DCD & 1.01 & $(1.004-1.013)$ \\
\hline Time, mo & 1.003 & $(0.991-0.015)$ \\
\hline Possible DCD $\times$ time & 0.989 & $(0.983-0.995)$ \\
\hline Female sex $\times$ time & & \\
\hline Obesity & 1.03 & $(0.76-1.38)$ \\
\hline Female sex & 0.79 & $(0.53-1.18)$ \\
\hline Age at baseline & 4.00 & $(2.57-6.21)$ \\
\hline Possible DCD & 0.998 & $(0.992-1.004)$ \\
\hline Time, mo & 1.012 & $(1.001-1.023)$ \\
\hline Possible DCD $\times$ time & 0.997 & $(0.989-1.006)$ \\
\hline Female sex $\times$ time & & \\
\hline
\end{tabular}

Note: $\mathrm{Cl}=$ confidence interval, $\mathrm{DCD}=$ developmental coordination disorder, $\mathrm{OR}=$ odds ratio.

mental coordination disorder were at higher risk for overweight throughout the study period than were children without the disorder. There was very little difference between boys and girls in both groups.

For obesity (Table 4), we found both a significant main effect of possible developmental coordination disorder and a significant interaction between the disorder and time. Similar to the analysis with overweight as the outcome, we found no evidence of an interaction between sex, time and possible developmental coordination disorder. Sex-related effects were very small in these models. Figure 4 shows the predicted probability of obesity, derived from the equation in Table 4 ,

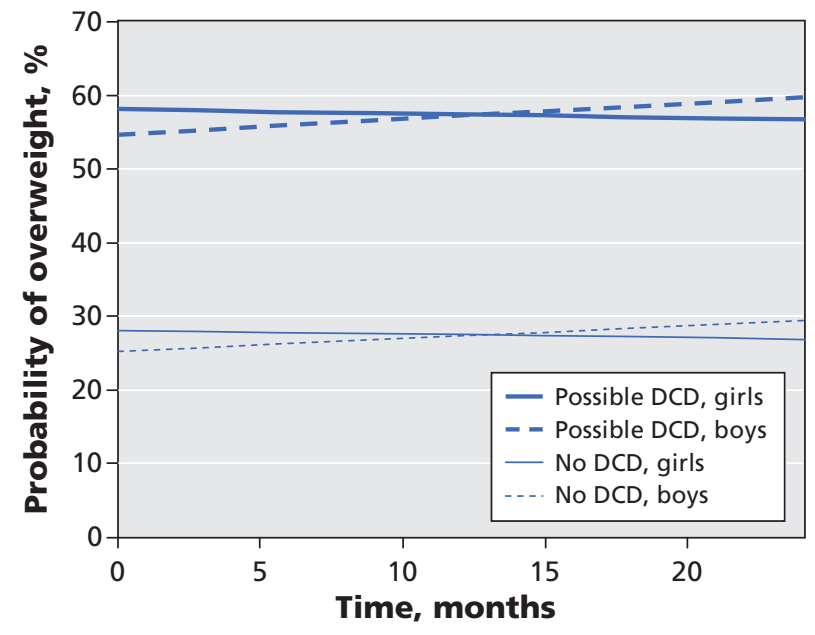

Figure 3: Predicted probability of overweight among children with and without possible developmental coordination disor$\operatorname{der}(D C D)$. among boys with and without possible developmental coordination disorder. To simplify the figure, we plotted values only for boys, but the values for girls were essentially identical. The risk for obesity increased over time among children with possible developmental coordination disorder, whereas the risk of obesity among children without the disorder remained relatively constant.

\section{Interpretation}

Consistent with findings from previous studies, we found that children with possible developmental coordination disorder had higher mean BMI values at baseline and were at greater risk of overweight and obesity than were children without the disorder. ${ }^{710}$ Perhaps most importantly, we found that differences in both BMI and waist circumference remained significant over time and even increased by the final assessment.

In contrast, in her analysis of children 5 to 7 years of age, Hands ${ }^{8}$ found neither a main effect of motor coordination on BMI, nor an interaction between time and motor coordination. Differences in the age composition of the samples between studies and the relatively small number of participants in Hands' study ( $n=38)$ may account for the contradictory findings.

When we focus on overweight and obesity, our results are remarkably consistent with those of Osika and Montgomery ${ }^{9}$ in that both studies showed an increased risk of overweight or obesity over time among children with coordination problems. Both studies reported odds ratios between three and four, even though the study by Osika and Montgomery ${ }^{9}$ examined the risk of obesity about 26 years after the initial assessment of clumsiness. Our results do differ, however, from an earlier study of developmental coordination disorder and obesity, which showed that the disorder was associated with obesity among boys but not among girls. ${ }^{7}$ The results of our current study suggest that the child's sex makes little difference to the risk of overweight or obesity in this population.

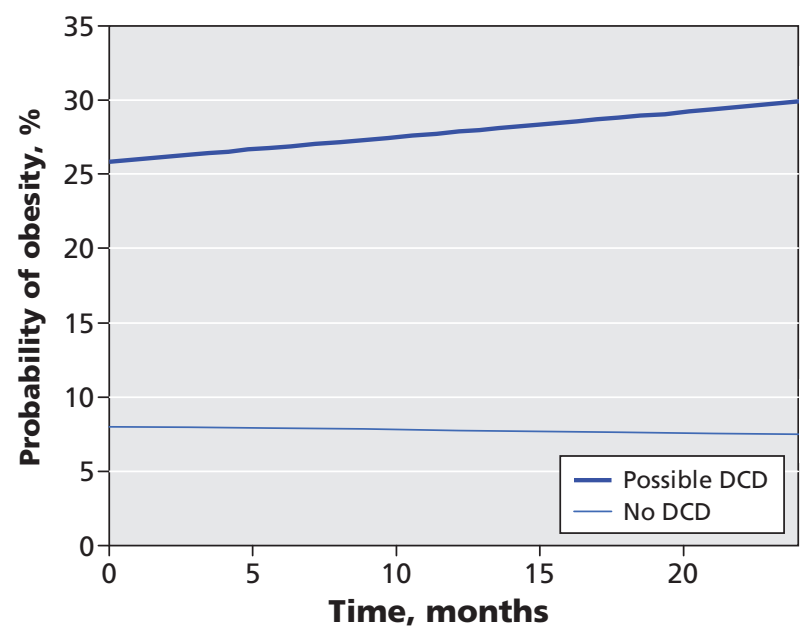

Figure 4: Predicted probability of obesity among boys with and without possible developmental coordination disorder (DCD). (Values for girls are not plotted because they were essentially identical to those for boys.) 


\section{Limitations}

Our study has limitations. First, developmental coordination disorder was not identified through clinical assessment by a physician; instead, it was identified by trained research assistants using a standardized screening instrument. Second, two of the four diagnostic criteria ${ }^{4}$ (criteria B and C) could not be fully addressed with this research design. The exclusion of criterion B in particular may have led to an overestimation of the disorder. ${ }^{27}$ Third, motor coordination testing was performed at different times for different students. Although developmental coordination disorder has been shown to develop very early and, in general, to persist throughout childhood, ${ }^{20,21}$ we cannot rule out the possibility that this feature of the study design influenced our results.

Finally, some uncertainty remains on the question of precedence. Although we have interpreted our results as showing that poor motor coordination may lead to increased weight, the opposite could be true: increased weight may lead to low scores on tests of motor proficiency. There is some evidence that obesity influences some aspects of coordination, such as dynamic balance, while leaving others, including fine motor skills, relatively unaffected. ${ }^{28} \mathrm{~A}$ high BMI may also reflect low activity levels and associated lack of practice in specific motor skills, rather than an inherent deficit in motor coordination. Osika and Montgomery, ${ }^{9}$ however, found that clumsiness at age 7 increased the risk of overweight or obesity at age 33, even after adjustment for BMI scores at ages 7 and 11. Resolving this question may require the tracking of both motor coordination and relative weight from very early ages.

\section{Conclusions}

Our findings from this large, population-based cohort showed that children with possible developmental coordination disorder were at greater risk of overweight and obesity than typically developing children. This risk did not diminish over the study period. Our results show that developmental coordination disorder was associated not only with social, academic and emotional and behavioural problems, but also with an important risk factor for cardiovascular disease and other disease. Although developmental coordination disorder has in the past been considered part of the normal continuum of motor proficiency or regarded as merely a "playground disorder" that is of lesser importance among children's health concerns, our results, along with those from other studies, suggest that this is no longer acceptable. The findings have important implications for intervention. There is a clear need to take a broader, longer-term view of the health consequences of developmental coordination disorder.

\section{This article has been peer reviewed.}

\section{Competing interests: None declared.}

Contributors: All of the authors contributed to the study concept and design. John Cairney, John Hay, Cheryl Missiuna, Nadilein Mahlberg and Brent Faught contributed to the study supervision and the acquisition of data. John Cairney and Scott Veldhuizen contributed to the analysis and interpretation of the data. John Cairney drafted the article, and the other authors critically revised it for important intellectual content. All of the authors gave final approval of the version to be published.
Funding: This study was funded by the Canadian Institutes of Health Research (grant no. 66959). John Cairney is supported by an endowed professorship from the Department of Family Medicine at McMaster University.

\section{REFERENCES}

1. Gibbs J, Appleton J, Appleton R. Dyspraxia or developmental coordination disorder? Unraveling the enigma. Arch Dis Child 2007;92:534-9.

2. Visser J. Developmental coordination disorder: a review of research on subtypes and comorbidities. Hum Mov Sci 2003;22:479-93.

3. Missiuna C, Moll S, King G, et al. "Missed and misunderstood": children with coordination difficulties in the school system. Int J Spec Educ 2006a;21:53-67.

4. American Psychiatric Association. Diagnostic and statistical manual of mental disorders, fourth edition, text revision. DSM IV-TR. Washington (DC): The Association; 2000. p. 58

5. Missiuna C, Gaines R, Soucie H. Why every office needs a tennis ball: a new approach to assessing the clumsy child. CMAJ 2006;175:471-3.

6. Bouffard M, Watkinson EJ, Thompson LP, et al. A test of the activity deficit hypothesis with children with movement difficulties. Adapt Phys Activ Q 1996; 13:61-73.

7. Cairney J, Hay JA, Faught BE, et al. Developmental coordination disorder and overweight and obesity in children aged 9 to 14 y. Int J Obes (Lond) 2005;29:369-72.

8. Hands B. Changes in motor skill and fitness measures among children with high and low motor competence: a five-year longitudinal study. J Sci Med Sport 2007; 11:155-62.

9. Osika W, Montgomery SM. Physical control and coordination in childhood and adult obesity: longitudinal birth cohort study. BMJ 2008;337:a699.

10. Schott N, Alof V, Hultsch D, et al. Physical fitness in children with developmental coordination disorder. Res Q Exerc Sport 2007;78:438-50.

11. Dietz WH, Robinson TN. Use of the body mass index as a measure of overweight in children and adolescents. J Pediatr 1998;132:191-3.

12. Pietrobelli A, Faith MS, Allison DB, et al. Body mass index as a measure of overweight in children and adolescents. J Pediatr 1998;132:204-10.

13. Taylor RW, Jones IE, Williams SM, et al. Evaluation of waist circumference, waist-to-hip ratio, and the conicity index as screening tools for high trunk fat mass, as measured by dual-energy x-ray absorptiometry, in children aged 3-19 y. Am J Clin Nutr 2000;72:490-5.

14. Han TS, Feskens EJ, Lean ME, et al. Associations of body composition with type 2 diabetes mellitus. Diabet Med 1998;15:129-35.

15. Okosun IS, Prewitt TE, Liao Y, et al. Association of waist circumference with ApoB to ApoAI ratio in black and white Americans. Int J Obes Relat Metab Disord 1999;23:498-504.

16. Martin NC, Piek JP, Hay D. DCD and ADHD: a genetic study of their shared aetiology. Hum Mov Sci 2006;25:110-24.

17. Gubbay SS. The clumsy child: a study in developmental apraxic and agnostic ataxia. London (UK): WB Saunders; 1975.

18. Cantell MH, Smyth MM, Ahonen TP. Clumsiness in adolescence: educational motor and social outcomes of motor delay detected at 5 years. Adapt Phys Activ $Q$ $1994 ; 11: 115-29$

19. Geuze RH, Borger H. Children who are clumsy: five years later. Adapt Phys Activ O 1993;10:10-21.

20. Hellgren L, Jilbergt C, Gillberg IC, et al. Children with deficits in attention, motor control and perception (DAMP) almost grown up: general health at 16 years. Dev Med Child Neurol 1993;35:881-92.

21. Losse A, Henderson SE, Elliman D, et al. Clumsiness in children - Do they grow out of it? A 10-year follow-up study. Dev Med Child Neurol 1991;33:55-68.

22. Cairney J, Hay JA, Veldhuizen S, et al. Comparing probable case identification of development coordination disorder using the short form of the BruininksOseretsky Test of Motor Proficiency and the Movement ABC. Child Care Health Dev 2009;35:402-8.

23. Gillum RF. Distribution of waist-to-hip ratio, other indices of body fat distribution and obesity and associations with HDL cholesterol in children and young adults aged 4-19 years: the Third National Health and Nutrition Examination Survey. Int J Obes Relat Metab Disord 1999;23:556-63.

24. Crawford SG, Wilson BN, Dewey D. Identifying developmental coordination disorder: consistency between tests. Phys Occup Ther Pediatr 2001;20:29-50.

25. Bruininks RH. Bruininks-Oseretsky Test of Motor Proficiency owner's manual. Circle Pines (MN): American Guidance Service; 1978.

26. Cole TJ, Bellizzi MC, Flegal KM, et al. Establishing a standard definition for child overweight and obesity worldwide: international survey. BMJ 2000;320:1240-3.

27. Lingam R, Hunt L, Golding J, et al. Prevalence of developmental coordination disorder using the DSM-IV at 7 years of age: a UK population-based study. Pediatrics 2009;123:e693-700.

28. D Hondt E, Deforche B, De Bourdeaudhuij I, et al. Relationship between motor skill and body mass index in 5- to 10-year old children. Adapt Phys Activ Q 2009; 26:21-37.

Correspondence to: Dr. John Cairney, Department of Family Medicine, 75 Frid St., Hamilton ON L8P 4M3;

cairnej@mcmaster.ca 